\title{
Determinants of child malnutrition in Bangladesh - A multivariate approach
}

\author{
Ahbab Mohammad Fazle Rabbi ${ }^{1}$, Shamal Chandra Karmaker ${ }^{2}$ \\ ${ }^{1}$ Bangladesh University of Textiles, Dhaka, Bangladesh, ${ }^{2}$ University of Dhaka, Dhaka, Bangladesh
}

\section{A B S T R A C T}

Objective: Malnutrition is referred as the greatest single threat to the world's public health, especially for the developing countries. Nutritional status is determined anthropometrically and it is outcome of complex interactions between biological, socio-economical variables. This study is conducted to identify the significant determinants of child malnutrition in Bangladesh. Method: Using BDHS-2007 data, Total 5312 cases are included in the present study. Multivariate techniques have been applied in this study to obtain significant determinants of child malnutrition. Results: Factor analysis revealed six factors as covariate of malnutrition; where two factors are socio-economical, others are biological and bio-social. Hence linear discriminant analysis is used to clarify the efficiency of obtained factors in malnutrition scenario; which imply that the obtained factors are accurate for approximately 60 percent observations. Conclusion: The obtained results suggest that, consciousness should be raised to improve socio-economic and maternal health conditions to improve the scenario of child malnutrition.

Key words: Anthropometric measures, Multivariate approach, Child malnutrition
Access this article online

Website:

http://nepjol.info/index.php/AJMS

DOI: $10.3126 / a j m s . v 6 i 2.10404$

\section{INTRODUCTION}

Malnutrition is described as a condition that results from taking an unbalanced diet in which certain nutrients are lacking, in excess (too high), or in the wrong proportions. Child nutrition status is an important indicator of poverty in a population; and poverty, malnutrition and disease are interlinked with each other. ${ }^{1}$ Malnutrition is an underlying cause of the death of 2.6 million children each year- onethird of the global total of children's deaths. ${ }^{2}$ Malnutrition is a significant determinant of various types of morbidity; is associated with an increased risk of death from ARI (acute respiratory infection), diarrhoea, measles and few other infectious diseases. Sometimes, Malnutrition causes serious alternation in physical growth and mental development of children. ${ }^{1}$ Previous studies have documented that severely malnourished children are at a much greater risk of dying than others. ${ }^{3}$ However, increased risk of mortality had been observed too, for children at moderate level of malnutrition. ${ }^{4}$ Considering the relative proportions of severe versus moderate malnutrition in populations, it showed that the majority of nutrition related deaths were significantly associated with moderate level, rather than severe level. ${ }^{4}$

To measure nutritional status, anthropometric measures as well as biomarkers are used. In practice, three standard indices of physical growth that describe the nutritional status of children are height-for-age (stunting); weight-forheight (wasting) and weight-for-age (underweight). Stunting is defined as a height-for-age measurement of below minus two-standard deviation of the median values compare to internationally based standard population, and is generally considered a marker of chronic malnutrition. ${ }^{5}$ A weightfor-height indicator defines acute malnutrition, termed as wasting. Another composite form of malnutrition, known as underweight or under-nutrition is defined with a weight-for-age indicator. ${ }^{5}$ All of these three indexes can be classified as severe and moderate levels according to the cut-off points defined by WHO (World Health Organization). ${ }^{5}$ 
Bangladesh, a developing country of Asia, also has notable child malnutrition circumstances. ${ }^{6}$ Vast literature exists on determinants of child nutrition status for developing countries including Bangladesh. Different studies have showed that several factors like low dietary intake, low birth weight, family size, lack of parental education, breast feeding status, incidence of diarrhoea, previous birth interval, mother's body mass index (BMI), household economic status and delayed weaning are closely related to infant and child malnutrition. ${ }^{7-11}$ The effect of sex and birth order of index child was a significant determinant of malnutrition in previous research. ${ }^{4}$ Socio-economic factors and diseases are also found to be significant determinant of child nutrition. ${ }^{12}$ Previous studies in Bangladesh have shown that malnutrition is a major risk factor for childhood mortality. ${ }^{13,14}$ Recent study reveals that malnutrition is higher in rural and hilly area compared to that of metropolitans and urban areas. ${ }^{15}$ Gender inequality due to socio-economic structure was significant differential of nutritional status of children in another study. ${ }^{16}$ Few studies suggested that, antenatal care seeking behavior of mother and related knowledge of health care are important determinant of child nutrition status, especially for infants. ${ }^{17}$

Most of the previous studies used regression models to identify the determinants associated with malnutrition. These regression models considered conventional dichotomous outcome variables for underweight, wasting and stunting. ${ }^{10}$ In current study, we explored the underlying factors that determine the nutrition status using multivariate approach instead of usual regression analysis. ${ }^{18}$ The benefit is remarkable- no more multicollinearity problem or heteroscedasticity problem; which are common in case of any study involving socio-economical variables. From a set of possible explanatory variable, we are exploring the possible underlying factors; which are determining malnutrition most plausibly.

\section{MATERIAL AND METHODS}

The data utilized for this study is a secondary data extracted from the Bangladesh Demographic and Health Survey conducted in 2007 under the authority of the National Institute for population Research and Training (NIPORT) of the Ministry of Health and Family Welfare. ${ }^{6}$ Stratified Multi-stage Cluster Sampling design is used to collect data and BDHS-2007 includes 10996 women of child bearing age of all six divisions in the country. The last birth from the last three years prior to BDHS-2007 survey has been considered for this study. Covariates are chosen on the basis of chi-square tests and previous studies. In current study, mother's age at birth and BMI, birth order and sex of index child, mother's antenatal care (ANC) visit pattern and currently breastfeeding status, preceding birth interval and record of live births, mother's educational and employment status, father's educational level, residence (regional and urban/rural), wealth index and mass media exposure status are considered as explanatory variables.

In BDHS-2007, the prevalence of malnutrition is calculated according to the report of WHO working group. ${ }^{5}$ Uses of Z-scores were recommended as it has some important advantages over other measures. ${ }^{6}$ These Z-scores can be calculated on the basis of the proportion of individuals in the observed population whose index is below minus 2 standard deviation of the index for the WHO's reference population. Prevalence of malnutrition is thus classified as severe and moderate if children with Z-scores below minus 3 standard deviations (-3SD) and children with Z-scores between minus 3 standard deviations (-3SD) and below minus 2 standard deviation (-2SD) from the median of the WHO's reference population respectively., 5,6 So, the different categories among children in terms of nutrition status became: well-nourished (Z-scores $\geq-2 \mathrm{SD}$ ), moderately malnourished $(-3 \mathrm{SD} \leq \mathrm{Z}$-scores $<-2 \mathrm{SD})$ and severely malnourished $(\mathrm{Z}$-scores $<-3 \mathrm{SD}){ }^{5}$

To extract the significant factors of nutritional status of under-five children of Bangladesh, factor analysis had been used in this study based on principal components. A factor can be thought of as a theoretical measure representing a group of actual measures that correlate highly with one another and lowly with the others in a set. The loadings are the correlations between the actual measures and the theoretical measures or factors. A factor is identified by an examination of the variables that load highly (that is, correlate highly) on it. Principal Component Analysis is used for extraction of factors and orthogonal rotation (varimax option) to derive non-correlated factors. ${ }^{18,19}$ Adequacy of factors was verified by Kaiser-Meyer-Olkin (KMO) measurement of adequacy. ${ }^{19}$ Factor loadings greater than 0.5 and cross-loading (loadings with negative value) less than -0.4 are taken into account to explain the relationship between the covariates and factors. ${ }^{20}$ Proportion of variation explained by a factor is its eigenvalue divided by the sum of all eigenvalues. The factor analysis arranges the latent roots by diminishing order that facilitates identification of the dominant structural factors. Besides Scree plot (Eigen plot); Kaiser Criterion (factor with eigenvalue greater than 1.0) is used for the choice of the number of factors in factor analysis. ${ }^{20}$

Next, to check the validity of findings from factor analysis discriminant analyses have been used for all the three indicators of nutritional status; i.e. which proportion of the observations are correctly classified according to the factors obtained from individual factor analysis. ${ }^{20}$ Linear Discriminant Analysis (LDA) is closely related to regression 
analysis, which also attempts to express one dependent variable as a linear combination of other features or measurements. For regression analysis, the dependent variable is a numerical quantity, whereas for LDA it is a categorical variable (i.e. the class label). ${ }^{20}$ Another benefit of using LDA is, it does not require the normality assumptions of usual regression techniques. Statistical analysis was performed using the SPSS (version 11.5) and R (2.15.1).

\section{RESULTS}

According to BDHS-2007, 17.4 percent of children are considered underweight for their height or wasted and 2.9 percent are severely wasted. 43.2 percent of children under age five are considered short for their age or stunted while 16.1 percent are severely stunted. 41 percent of children are underweight (low weight-for-age), and 11.8 percent are severely underweight. ${ }^{6}$ The distributions of Z-scores for all three nutrition indices are presented in the following figure (Figure 1).

Both socio-demographic and proximate covariates are possible determinant of nutritional status. As these variables are not of same types, the strength and direction of all covariates of nutritional status will not be same. In this context, our first step is to search for significant factors of nutritional status of under-five children and the second step is to find the direction of covariates from those dominant factors. Rotated component matrix obtained from factor analysis is presented in the following table (Table-1).

As the factors are obtained from several types of socioeconomical, biological and birth history variables, the obtained factors are quite theoretical in nature rather than practical to name. Total six factors have been revealed from the factor analysis, and they account for about $62 \%$ of the observed variation in the possible socio-economical/ health/biological variables determining malnutrition (see Table-2).

A scree plot for all of the variables used in the study is showed in the following figure, i.e. the graphical spatial representation of derived factors for malnutrition. The parallel line to horizontal at Eigen value equaling to 1.0 in scree plot showed that the extracted six factors for nutritional status of the under-five children for BDHS 2007 (Figure-2).

The first factor is highly correlated with educational level of parents, wealth index, mother's exposure level to mass media and number of antenatal visit conducted by mother prior to index birth. In this context, this factor can be named as 'consciousness factor'; clearly all of the high loadings were obtained for the conscience of parents for mother and newborn's health. Clearly, as the parents are higher educated, as much they are exposed to mass media, the likelihood of child malnutrition will be decrease in the inverse pattern of consciousness factor. The second factor can be named as 'birth history factor-1', as this factor has high loadings with mother's age at birth and birth order of index child. It should be mentioned that there are another obtained factor which also has high factor loadings birth history factors, that's why that factor is named as 'birth history factor-2' eventually. That is the last significant factor having lowest eigenvalue and lowest explained variance among all factors. That factor has high loading with prior record of any live birth and gender of index child.

The significant role of provincial and regional impact on nutritional status can be seen in current study. The third factor has high factor loading with division and cross loading

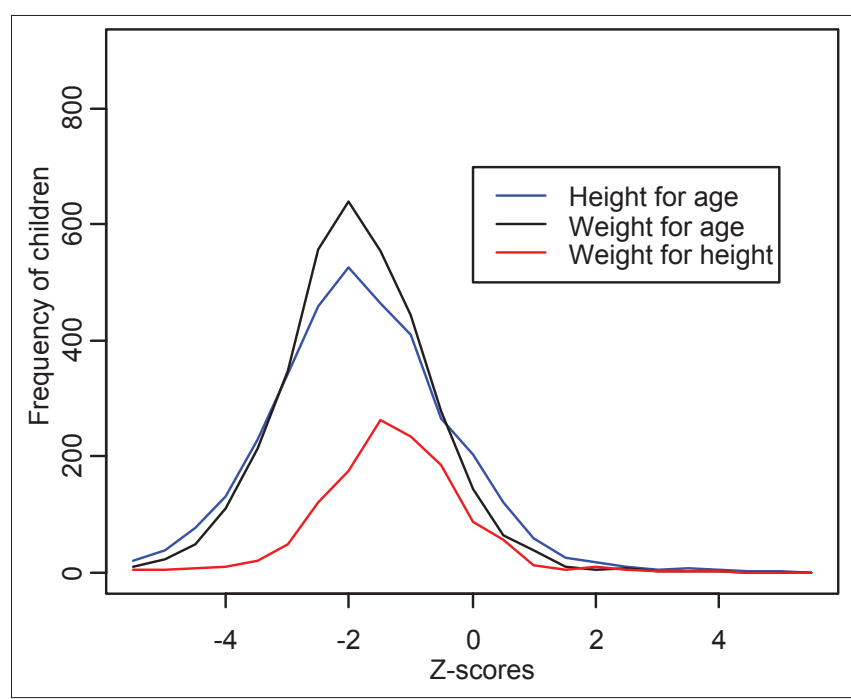

Figure 1: Distribution of Z-scores for nutritional status of under-five children of Bangladesh (BDHS-2007)

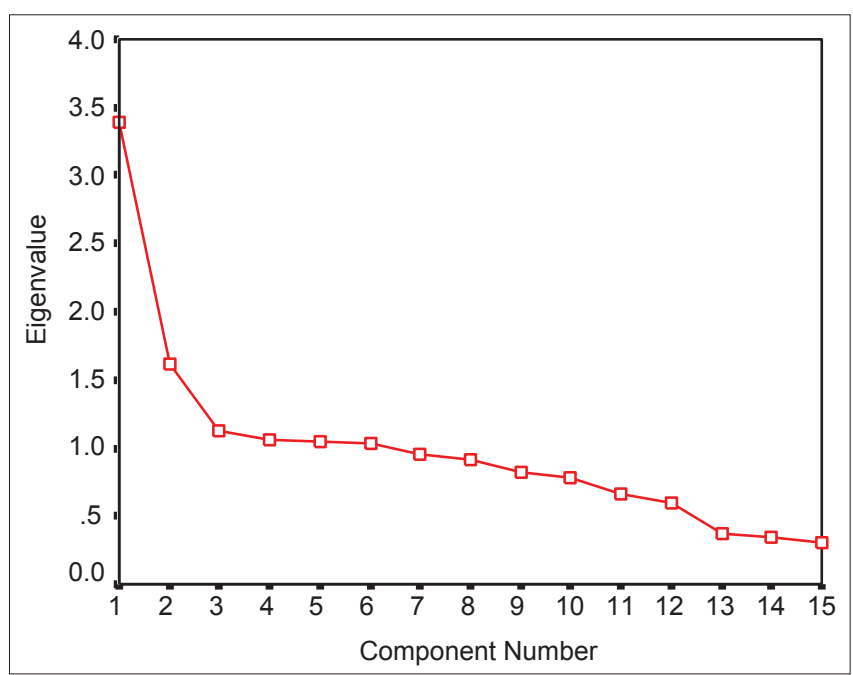

Figure 2: Scree Plot for nutritional status of under-five children of Bangladesh (BDHS-2007) 


\begin{tabular}{|c|c|c|c|c|c|c|}
\hline \multirow[t]{2}{*}{ Variables } & \multicolumn{6}{|c|}{ Components } \\
\hline & 1 & 2 & 3 & 4 & 5 & 6 \\
\hline Division & 0.034 & 0.070 & 0.805 & 0.025 & 0.120 & 0.009 \\
\hline Type of place of residence & -0.208 & -0.058 & -0.569 & -0.255 & 0.154 & 0.104 \\
\hline Mother's educational level & 0.685 & -0.276 & -0.222 & -0.200 & 0.101 & 0.055 \\
\hline Wealth index & 0.825 & 0.024 & 0.112 & -0.056 & -0.097 & -0.019 \\
\hline Sex of child & -0.059 & -0.045 & -0.165 & 0.132 & 0.176 & 0.717 \\
\hline Live birth between births & 0.073 & 0.064 & 0.190 & -0.099 & -0.196 & 0.700 \\
\hline Preceding birth interval & 0.206 & 0.327 & -0.350 & 0.407 & 0.683 & -0.042 \\
\hline Mother's age at birth & 0.030 & 0.908 & -0.012 & 0.622 & 0.064 & 0.027 \\
\hline Mass media exposure status & 0.706 & -0.123 & 0.097 & 0.088 & -0.030 & -0.004 \\
\hline Mother's employment status & -0.116 & -0.072 & 0.036 & 0.834 & -0.078 & 0.046 \\
\hline Father's education level & 0.688 & -0.068 & -0.199 & -0.241 & 0.056 & 0.052 \\
\hline Birth order of index child & -0.308 & 0.792 & 0.091 & -0.091 & -0.141 & -0.008 \\
\hline Frequency of anc visit & 0.659 & -0.054 & -0.003 & 0.009 & 0.081 & 0.039 \\
\hline Mother's bmi (grouped) & 0.455 & 0.090 & -0.268 & -0.048 & 0.609 & -0.039 \\
\hline Duration of breastfeeding & -0.118 & -0.088 & 0.204 & -0.139 & 0.797 & -0.003 \\
\hline
\end{tabular}

**Extraction method: Principal component analysis. Rotation method: Varimax with Kaiser Normalization. Rotation converged in 11 iterations

\begin{tabular}{|c|c|c|c|c|c|c|c|c|c|}
\hline \multirow[t]{2}{*}{ Components } & \multicolumn{3}{|c|}{ Initial eigenvalues } & \multicolumn{3}{|c|}{ Extraction sums of squared loadings } & \multicolumn{3}{|c|}{ Rotation sums of squared loadings } \\
\hline & Total & $\%$ of variance & Cumulative $\%$ & Total & $\%$ of variance & Cumulative $\%$ & Total & $\%$ of variance & Cumulative \% \\
\hline 1 & 3.386 & 22.573 & 22.573 & 3.386 & 22.573 & 22.573 & 3.263 & 21.752 & 21.752 \\
\hline 2 & 1.614 & 10.763 & 33.336 & 1.614 & 10.763 & 33.336 & 1.692 & 11.283 & 33.035 \\
\hline 3 & 1.128 & 7.519 & 40.855 & 1.128 & 7.519 & 40.855 & 1.111 & 7.408 & 40.443 \\
\hline 4 & 1.060 & 7.065 & 47.920 & 1.060 & 7.065 & 47.920 & 1.093 & 7.286 & 47.728 \\
\hline 5 & 1.052 & 7.016 & 54.936 & 1.052 & 7.016 & 54.936 & 1.080 & 7.202 & 54.930 \\
\hline 6 & 1.029 & 6.858 & 61.794 & 1.029 & 6.858 & 61.794 & 1.029 & 6.863 & 61.794 \\
\hline
\end{tabular}

with place of residence (urban/rural). That's why it can be named as 'residence factor'. It is hard to name the fourth factor, as it has high loadings with mother's age at birth and employment status. Malnutrition decreases with the increase of mother's age and its lower for mother's having their birth after adolescence period. Again, the impact of employment remains; employed mothers can summarize information about food intake and nutrition status of children of other employed collogues which guide them to improve diet and nutrition status of thy children. ${ }^{2}$ This factor may be named as 'mother's capability factor'; as it considers both social and physical capability of mother which decline malnutrition.

One of the most important biological factors has been obtained as the fifth factor of nutritional status. This factor has high loadings with previous birth interval, mother's BMI and breast feeding status. All of the previous studies mentioned these variables as important determinant of child nutrition. It has been observed the likelihood of being malnourished is higher for those births having previous birth interval less than 24 months, breast feed less than 24 months., ${ }^{211}$ Longer birth intervals are also better for mother's health, longer intervals allow parents to devote more time to each child in the early years, easing pressures on the family's finances and giving parents more time for activities other than child rearing. ${ }^{9}$ Again, mother's BMI is predicted as an important determinant of child malnutrition. ${ }^{8,9}$ So, considering all the facts, this factor can be named as 'mother's health and breast feeding factor'.

Linear Discriminant Analysis is used for studying the relationship between the obtained factors (in factor analysis) and child nutrition status. The factor scores obtained by the factor analysis for nutritional status were considered continuous independent variables, and three indicators of nutritional status is considered as dichotomous dependent variable. For all of these indexes, two groups had been considered for this analysis; either malnourished or wellnourished. The reason behind such groupings is to know the efficiency of our findings for malnourished children precisely and to avoid computational complexity along with explanation. According to the obtained factors in factor analysis; for height-for-age, weight-for-age and weight-for-height, 58.7 percents, 57.8 percents and 58.4 percents observations were appropriately classified respectively. The results of linear discriminant analysis are summarized in the following Table-3. 


\begin{tabular}{|c|c|c|c|}
\hline \multicolumn{4}{|l|}{ Height for age z-scores ${ }^{(a)}$} \\
\hline \multirow[t]{2}{*}{$\begin{array}{l}\text { Nutritional status } \\
\text { (according to haz scores) }\end{array}$} & \multicolumn{2}{|c|}{$\begin{array}{l}\text { Predicted group } \\
\text { membership }\end{array}$} & \multirow[t]{2}{*}{ Total } \\
\hline & $\begin{array}{c}\text { Well } \\
\text { nourished }\end{array}$ & Malnourished & \\
\hline Original Count Well nourished & 750 & 625 & 1375 \\
\hline Malnourished & 332 & 610 & 942 \\
\hline Well nourished & 54.5 & 45.5 & 100.0 \\
\hline Malnourished & 35.2 & 64.8 & 100.0 \\
\hline \multicolumn{4}{|c|}{ (a) $58.7 \%$ of original grouped cases correctly classified } \\
\hline \multicolumn{4}{|l|}{ Weight for age z-scores ${ }^{(b)}$} \\
\hline \multirow[t]{2}{*}{$\begin{array}{l}\text { Nutritional status } \\
\text { (according to waz scores) }\end{array}$} & \multicolumn{2}{|c|}{$\begin{array}{l}\text { Predicted group } \\
\text { membership }\end{array}$} & Total \\
\hline & $\begin{array}{c}\text { Well } \\
\text { nourished }\end{array}$ & Malnourished & \\
\hline \multirow{2}{*}{$\begin{array}{r}\text { Original Count Well nourished } \\
\text { Malnourished }\end{array}$} & 763 & 665 & 1428 \\
\hline & 339 & 589 & 928 \\
\hline \multirow{2}{*}{$\begin{array}{ll}\% \quad \text { Well nourished } \\
\text { Malnourished }\end{array}$} & 53.4 & 46.6 & 100.0 \\
\hline & 36.5 & 63.5 & 100.0 \\
\hline \multicolumn{4}{|c|}{ (b) $57.4 \%$ of original grouped cases correctly classified } \\
\hline \multicolumn{4}{|l|}{ Weight for height z-scores(c) } \\
\hline $\begin{array}{l}\text { Nutritional status } \\
\text { (according to whz scores) }\end{array}$ & \multicolumn{2}{|c|}{$\begin{array}{l}\text { Predicted group } \\
\text { membership }\end{array}$} & Total \\
\hline & $\begin{array}{c}\text { Well } \\
\text { nourished }\end{array}$ & Malnourished & \\
\hline Original Count Well nourished & 411 & 321 & 732 \\
\hline Malnourished & 48 & 106 & 154 \\
\hline Well nourished & 56.1 & 43.9 & 100.0 \\
\hline Malnourished & 31.2 & 68.8 & 100.0 \\
\hline
\end{tabular}

The dichotomous classification for each of the indices is made according to report of $\mathrm{WHO}$ working group. ${ }^{5}$ Prevalence of malnutrition is thus classified as malnourished if children with Z-scores below minus 2 standard deviation (-2SD), else it has been classified as well-nourished. For height-for-age z-scores, 54.5 percents of the nourished children are correctly classified while for malnourished 64.8 percents of the malnourished children are correctly classified. In other words, sensitivity of discriminant function was 54.5 percents and the specificity was 64.8 percents in case of stunting. Next, for weight-forage; 53.4 percents of the nourished children are correctly classified while for malnourished 63.5 percents of the malnourished children are correctly classified. For wasting, sensitivity of discriminant function was 56.1 percents while specificity was 68.8 percents.

\section{DISCUSSION}

The World Health Organization cites malnutrition as the greatest single threat to the world's public health. Improving nutrition is widely regarded as the most effective form of aid. So the studies of determinants of child malnutrition provide valuable suggestions to the health care providers and planners of public health sector of a country; especially for a country like Bangladesh where, 17 percent of underfive children are wasted, 43 percent of stunted and 41 percent of children are underweight. ${ }^{6}$

Current study includes both socio-economic and biosocial variables. For statistical significance, multivariate techniques have been applied in this study; as these methods can overcome the problems of usual regression analysis (in terms of multicollinearity and heteroscedasticity). Using factor analysis total six possible factors had been determined. They are named according to their loadings and cross-loadings from rotated component matrix. The first factor is named as 'consciousness factor', next; 'birth history factor-1'; 'residence factor'; 'mother's capability factor', 'mother's health and breast feeding factor' and 'birth history factor-2' respectively according to amount of explained variation. These six factors explained 62 percent of total variation from a cluster of 15 independent variables. Next to verify the applicability of the obtained factors to current nutritional status of children of Bangladesh; Linear Discriminant Analyses are performed for all three indices. The nutritional indices are classified into two groups, wellnourished and malnourished according to report of WHO working group. ${ }^{5}$ For all of the three indices we find that our obtained factors are explaining approximately 60 percent of the observations appropriately.

Though malnutrition is a health hazard for under-five children, results from previous studies and current study it is clear that, pre-birth factors like mother's age at birth, preceding birth interval, adequate antenatal care of mother play vital role on infant physical condition and later on nutrition status. ${ }^{4,17}$ Special attention is needed on those sectors for healthy and well nourished infant. For safe motherhood and neonatal health, lengthy birth intervals are suggested in old studies; at least 4 antenatal care visits is required for both infant and mothers good. ${ }^{1,4,10}$ It is an established fact that adolescent mothers are in higher risk for give birth of live births and severely ill birth. ${ }^{4}$ Bigger family size that is population problem is also responsible for malnutrition, as higher parity causes giving birth of live births and malnourished birth, which is indicated by the correlation between birth order and malnutrition. ${ }^{9}$ Another possible explanation is, it is difficult to maintain the proper health and dietary intake for a large family compare to that of small families. Prolonged breastfeeding is usually available in Bangladesh, but opposite one is also seen. ${ }^{4}$ Practice of breastfeeding should be given priority and mothers should be notified by health care providers to feed colostrums immediately after giving birth to the newborn, which is an immense nutrient shield for a newborn. 
Various frequent clusters are also present on nutrition status of children. In developing countries, regional variance is a common determinant of various public health indicators, current study also indicates the same. ${ }^{2}$ The third factor was residence factor; rural children suffer more for under nutrition problem, similarly nutrition scenario is not same for all the divisions. Special campaign is needed for rural areas and certain districts for improving the scenario, rural mothers should be encouraged for seeking child care in government facilities and NGO's satellite clinic., ${ }^{2,47}$ Another well differential can be seen according to wealth index; malnutrition ratios are less in rich families compared to poor families.

Despite of all determinants and differentials of malnutrition, consciousness plays the most important role. Almost all of the previous studies conclude about consciousness, as the main differential of child nutritional status. ${ }^{11,15}$ Education builds this consciousness among mothers, which increases the mothers and child health care seeking behavior. Mass media can play vital role on increasing education rate, which in result create consciousness among parents. Gendereffect is still present as determinant of child malnutrition (prevalence of malnutrition is higher in case of female child), which is not expected in twenty first century. ${ }^{4}$ Rise of women education is necessary in the way to overcome it. And finally, various effects of socio-economic burdens (like gender, religious factors) can be removed by proper use of huge mass media campaign to raise consciousness against malnutrition and its consequences.

\section{ACKNOWLEDGEMENT}

The authors are grateful to Dr. N. Alam (CPUCC, ICDDR,B), for his suggestions about the nutritional z-scores.

\section{REFERENCES}

1. Rice AL, Sacco L, Hyder A and Black RE. Malnutrition as an underlying cause of childhood deaths associated with infectious diseases in developing countries. Bulletin of World Health Organization 2000; 78(10):1207-1221.

2. McGregor GS, Cheung YB, Cueto S, Glewwe P, Richter $L$ and Strupp B. Development potential in the first 5 years for children in developing countries. The Lancet 2007; 369(9555):60-70.

3. Gomez P, Ramos Galvan RR, Frenk S, Cravioto Muñoz J, Chávez R and Vázquez J. Mortality in second and third degree malnutrition. Journal of Tropical Pediatrician 1956; 2(2):77-83.
4. Bairagi R and Chowdhury MK. Socio-economic and anthropometric status and mortality of young children in rural Bangladesh. International Journal of Epidemiology 1994; 23:1197-1281.

5. World Health Organization. Use and Interpretation of Anthropometric Indicators of Nutritional Status. Bulletin of World Health Organization 1986; 64(6):929-941.

6. NIPORT, Mitra and Associates \& ORC Macro. Bangladesh Demographic and Health Survey 2007. National Institute of Population Research and training (NIPORT), Mitra and Associates and ORC Macro, Calverton, MD; 2009.

7. Bégin F, Habicht JP, Frongillo EA and Delisle H. The deterioration in children's nutritional status in rural Chad: the effect of mothers' influence on feeding. American Journal of Public Health 1997; 87(8):1356-1359.

8. Rayhan I, Khan MSH and Shahidullah M. Impacts of biosocial factors on morbidity among children aged under-5 in Bangladesh. Asia Pacific Population Journal 2007; 22(1):65-75.

9. Das $\mathrm{S}$, Hossain MZ and Islam MA. Predictors of child chronic malnutrition in Bangladesh. Proceedings of Pakistan Academy of Science 2008; 45(3):137-155.

10. Rahman A, Chowdhury $S$ and Hossain D. Acute malnutrition in Bangladeshi children. Asia Pacific Journal of Public Health 2009; 21(3):294-302.

11. Siddique MNA, Haque $M N$ and Goni MA. Malnutrition of underfive children: Evidence from Bangladesh. Asian Journal of Medical Science 2011; 2:113-119.

12. Madzingira N. Malnutrition in children under five in Zimbabwe: effect of socioeconomic factors and disease. Social Biology 1995; 42(3-4):239-246.

13. Chen LC, Chowdhury AKMA and Huffman SL. Anthropometric assessment of Energy-Protein malnutrition and subsequent risk of mortality among preschool aged children. American Journal of Clinical Nutrition 1980; 33:1836-1845.

14. Roy SK, Chowdhury AKMA and Rahman MM. Excess mortality among children discharged from hospital after treatment for diarrhoea in rural Bangladesh. British Medical Journal 1983; 287: 1097-1099.

15. Muaz SSA, Hasan MR, Shamim SA, Dev A and Kamar S. Nutritional status of 1-5 years children of the Tea Workers in Sylhet division. Bangladesh Journal of Child Health 2010; 34(1):11-16.

16. Rousham EK. Socio-economic influences on gender inequalities in child health in rural Bangladesh. European Journal of Clinical Nutrition 1996; 50(8):560-564.

17. Cochrane SH, Leslie J and O'Hara DJ. Parental education and child health: intracountry evidence. Health Policy and Education 1982; 2(3-4):213-250.

18. Hair JF, Anderson RE, Tatham RL and Black WC. Multivariate Data Analysis with Reading. $4^{\text {th }}$ ed. New Jersy: Prentice Hall, 1995.

19. Mardia KV, Kent JM and Bibby JM. Multivariate Analysis. London: Academic press, 1980.

20. Johnson RA and Wichern DW. Applied Multivariate Statistical Data Analysis. New Jersey: Prentice Hall, 2002. 